\title{
Characteristics and Disparities among Primary Care Practices in the United States
}

\author{
David Michael Levine, MD MPHMA ${ }^{1,2}$, Jeffrey A. Linder, MD MPH ${ }^{3}$, and Bruce E. Landon, MD MBA \\ $M S c^{2,4,5}$
}

'Division of General Internal Medicine and Primary Care , Brigham Health, Boston, MA, USA; ${ }^{2}$ Harvard Medical School, Boston, MA, USA; ${ }^{3}$ Division of General Internal Medicine and Geriatrics, Northwestern University Feinberg School of Medicine, Chicago, IL, USA; ${ }^{4}$ Department of Health Care Policy, Harvard Medical School, Boston, MA, USA; ${ }^{5}$ Division of General Medicine and Primary Care, Beth Israel Deaconess Medical Center, Boston, MA, USA.

BACKGROUND: Despite new incentives for US primary care, concerns abound that patient-centered practice capabilities are lagging.

OBJECTIVE: Describe the practice structure, patientcentered capabilities, and payment relationships of US primary care practices; identify disparities in practice capabilities.

DESIGN: Analysis of the 2015 Medical Organizations Survey (MOS), part of the nationally representative Medical Expenditure Panel Survey (MEPS).

SETTING: Practice-reported information from primary care practices of MEPS respondents who reported receiving primary care and made at least one visit in 2015 to that practice.

PARTICIPANTS: Surveyed primary care practices $(n=$ $4318 ; 77 \%$ response rate) providing primary care to 7161 individuals, representing 101,159,263 Americans.

MAIN MEASURES: Practice structure (ownership and personnel); practice capabilities (certification as a patientcentered medical home [PCMH], electronic health record [EHR] use, and x-ray capability); and payment orientation (accountable care organization [ACO] and capitation).

KEY RESULTS: Independently owned practices served $55 \%$ of patients, hospital-owned practices served 19\%, and nonprofit/government/academic-owned served $20 \%$. Solo practices served $25 \%$ of patients and practices with 2-10 physicians served 53\% of patients. Forty-one percent of patients were served by practices certified as PCMHs. Practices with EHRs cared for $90 \%$ of patients and could exchange secure messages with $78 \%$ of patients. Practices with in-office $\mathrm{x}$-ray capability cared for $34 \%$ of patients. Practices participating in ACOs and capitation served $44 \%$ and $46 \%$ of patients, respectively. Primary care patients in the South, compared to the rest of the country, had less access to nearly all practice capabilities, including patient care coordination (adjusted difference, 13\% [95\% CI, 8-18]) and secure EHR messaging (adjusted difference, 6\% [95\% CI, 1-10]). Uninsured patients were less likely to be served at a practice that used an EHR (adjusted difference, 9\% [95\% CI, 2-16]).

Dr. Jeffrey A. Linder and Dr. Bruce E. Landon contributed equally to this manuscript.

Received July 13, 2017

Revised October 30, 2017

Accepted November 9, 2017

Published online December 4, 2017
CONCLUSIONS: Participants' primary care practices were mostly independently owned, nearly always used EHRs (albeit of varying capability), and frequently participated in innovative payment arrangements for a portion of their patients. Patient practices in the South had fewer capabilities than the rest of the country.

KEY WORDS: primary care; practice characteristics; disparities in primary care.

J Gen Intern Med 33(4):481-6

DOI: $10.1007 / \mathrm{s} 11606-017-4239-Z$

(C) Society of General Internal Medicine 2017

\section{INTRODUCTION}

Primary care practices form the backbone of comprehensive health care delivery in the United States ${ }^{1,2}$ and throughout the developed world. ${ }^{3,4}$ Comprehensive primary care is associated with lower costs, improved health outcomes, greater efficiency, and reduced disparities. ${ }^{5}$ Despite the importance of primary care, concerns abound that practice capabilities are lagging. Additionally, concerns exist that practices are merging or being purchased by health systems and hospitals, ${ }^{6,7}$ which may bring advantages of care coordination and disadvantages of higher prices. 8,9

To bolster primary care, recent federal policy initiatives provide strong incentives to primary care practices to enter new payment relationships and to upgrade their patientcentered capabilities. The American Recovery and Reinvestment Act of 2009 included $\$ 30$ billion to promote adoption of electronic health records. ${ }^{10}$ The Affordable Care Act of 2010 introduced risk-sharing in accountable care organizations and enacted penalties for preventable readmissions. Most recently, the Medicare Access and CHIP Reauthorization Act (MACRA) of 2015 will shift physician reimbursement in Medicare toward a value-based system, tying payments to quality and cost performance through one of two mechanisms: participation in an advanced alternative payment model (e.g., an accountable care organization with downside risk) or in the Merit-based Incentive Payment System.

These programs may inadvertently result in consolidation among primary care practices, including mergers between independent practices or acquisitions by hospitals or larger 
health systems, in order to fund the large investments needed in this environment. ${ }^{6}$ Timely data are lacking as to the extent of consolidation, how it might impact the capabilities of primary care practices to deliver high-value care, and disparities in practice capabilities. In addition, current efforts to improve the delivery of primary care through the patient-centered medical home have yielded inconsistent effects on quality, though these efforts may evolve and strengthen over time. ${ }^{12,13}$ Data on practice capabilities would enable policymakers to craft informed policies that target specific deficits both nationally and for traditionally underserved populations. We analyzed recent nationally representative data to summarize trends in consolidation, participation in value-based models, and disparities in practice capabilities.

\section{METHODS}

\section{Data Source and Study Population}

We analyzed data from the 2015 Medical Expenditure Panel Survey (MEPS), a nationally representative annual survey of repeated cross sections of the non-institutionalized United States civilian population. ${ }^{14}$ The MEPS sample is drawn from respondents to the annual National Health Interview Survey. The MEPS uses a complex survey design that delivers English or Spanish computer-assisted interviews and collects detailed data on demographic characteristics, health conditions, health status, medical services utilization, medications, costs, source of payments, health insurance coverage, income, and employment. We included participants of all ages.

The MEPS determines whether a participant had a usual source of care (USC) by asking if a respondent had a clinician to which "you usually go if you are sick or need advice about your health." In 2015, MEPS sampled 33,893 participants (point-in-time response rate, 52\%), of whom 25,811 had a USC and 11,188 had at least one visit with their USC (hereafter termed "patients").

In 2015, the MEPS fielded a new supplemental questionnaire, the Medical Organizations Survey File (MOS), with the goal of detailing the organizational and financial characteristics of the office-based USC practice identified by each patient who had made a visit to their USC in the last year. The MOS questions were answered via telephone, mostly by office managers or practice administrators. Of the 11,188 patients, 9494 being seen in 5588 unique practices gave permission for their practice to be contacted. Ultimately, 4318 practices responded (77\% practice response rate), which served 7350 patients, of which 7161 had a positive person-weight. Because the practice data are linked to patients in the MEPS, all results refer to the percentage of patients cared for in practices with specified characteristics or capabilities. For example, when we describe use of an electronic health record (EHR), we report that $90 \%$ of patients were served at practices with EHRs, not that $90 \%$ of practices used EHRs, although these numbers are likely quite similar due to minimal patient overlap.

\section{Sensitivity Analysis}

To be confident that "USC" and "primary care" were analogous, we conducted a sensitivity analysis by considering a patient as having primary care only if they would see their USC for all four of the following: "new health problems"; "preventive health care, such as general checkups, examinations, and immunizations"; "referrals to other health professionals when needed"; and "ongoing health problems." With this more exclusive definition, of the 7161 USC patients, 6865 met this definition of primary care. We observed no substantive differences in practice characteristics or disparities, and therefore use "USC" and "primary care" interchangeably.

\section{Practice Characteristic Measures}

The MOS determined a practice's organizational structure (ownership, number of locations, whether multispecialty) and the number of physicians, advanced practice clinicians, and primary care physicians. It also collected data on each practice's capabilities, including certification as a patientcentered medical home (PCMH); use of case managers; use of an electronic health record (EHR) and associated EHR capabilities; follow-up timeliness; same-day appointment availability; in-clinic $\mathrm{x}$-ray capabilities; and whether physicians received personalized quality reports. Finally, the MOS asked whether physicians were paid a base salary, whether a practice had capitated contracts, and whether a practice participated in an accountable care organization (ACO). Notably, the percentage of contracts in an innovative payment model (capitation or ACO) was not captured, only that services for some portion of the practice's patients were reimbursed in an innovative manner, unlike the dominant fee-for-service model.

\section{Disparities in Practice Capabilities}

To examine whether practice capabilities differed for practices caring for underserved populations, we performed multivariable regression to obtain adjusted estimates for each practice capability, adjusting for all variables in Table 1 except the disparity variable of interest. We examined groups with characteristics known to be associated with poor access to highfunctioning health care, including black race/ethnicity, lack of insurance, geographic location in the South, and less than high school education. ${ }^{15-17}$ We also examined practices serving children versus adults.

\section{Statistical Analysis}

In all analyses we accounted for the complex design of the MEPS to allow for national estimates, applying personweights, strata, and clusters to adjust for non-response. ${ }^{18,19}$ In addition to these standard weighting procedures, weighting for the MOS adjusted for lack of permission, non-response, and key demographic subgroups. ${ }^{20}$ We present weighted percentages. 
We performed all analyses with SAS statistical software version 9.4 (SAS Institute Inc., Cary, NC, USA). We considered two-sided $p<0.05$ to be significant. The Harvard Medical School institutional review board determined that this study was not human subjects research and was therefore exempt from approval.

Table 1 Characteristics of Americans with at Least One Primary Care Visit, 2015

\begin{tabular}{|c|c|}
\hline Characteristic & $\begin{array}{l}\text { Mean \% } \\
(95 \% \mathrm{CI})^{*} \\
(n=7161 \\
\text { patients) }\end{array}$ \\
\hline AGE, mean years $(95 \% \mathrm{CI})$ & $40(39,41)$ \\
\hline FEMALE & $55(54,57)$ \\
\hline \multicolumn{2}{|l|}{ RACE/ETHNICITY } \\
\hline Non-Hispanic white & $62(59,65)$ \\
\hline Hispanic & $18(15,20)$ \\
\hline Non-Hispanic black & $11(9,12)$ \\
\hline Non-Hispanic Asian & $5(4,6)$ \\
\hline Non-Hispanic other or multiple & $5(4,6)$ \\
\hline \multicolumn{2}{|l|}{ CENSUS REGION } \\
\hline Northeast & $19(15,22)$ \\
\hline Midwest & $21(18,23)$ \\
\hline South & $36(33,40)$ \\
\hline West & $25(22,28)$ \\
\hline \multicolumn{2}{|l|}{ PARTNER STATUS } \\
\hline Married/partnered & $52(50,55)$ \\
\hline Never married & $9(8,10)$ \\
\hline Divorced/separated & $13(12,15)$ \\
\hline Widowed & $25(24,27)$ \\
\hline \multicolumn{2}{|l|}{ EDUCATION } \\
\hline$<$ High school & $31(29,33)$ \\
\hline High school/GED/some college & $45(43,47)$ \\
\hline Bachelor's degree & $15(13,16)$ \\
\hline$>$ Bachelor's degree & $9(8,11)$ \\
\hline \multicolumn{2}{|l|}{ HEALTH INSURANCE COVERAGE } \\
\hline Any private & $62(59,64)$ \\
\hline Public only & $34(32,37)$ \\
\hline Uninsured & $4(3,5)$ \\
\hline \multicolumn{2}{|l|}{ PERCEIVED HEALTH STATUS ${ }^{\dagger}$} \\
\hline Excellent & $30(28,32)$ \\
\hline Very good & $30(29,32)$ \\
\hline Good & $25(23,26)$ \\
\hline Fair & $11(10,12)$ \\
\hline Poor & $4(3,4)$ \\
\hline EMPLOYED ${ }^{\dagger}$ & $58(56,60)$ \\
\hline CURRENTLY SMOKE ${ }^{\dagger}$ & $10(9,11)$ \\
\hline ADL HELP & $4(3,4)$ \\
\hline iADL HELP ${ }^{\ddagger}$ & $6(5,7)$ \\
\hline SF-12 PHYSICAL COMPONENT & $47(46,47)$ \\
\hline SUMMARY $^{\dagger}$ & \\
\hline SF-12 MENTAL COMPONENT SUMMARY ${ }^{\dagger}$ & $51(51,51)$ \\
\hline KESSLER INDEX $^{\dagger \S}$ & $3(3,4)$ \\
\hline BODY MASS INDEX, mean $\mathrm{kg} / \mathrm{m}^{2}(95 \% \mathrm{CI})^{\dagger}$ & $29(28,29)$ \\
\hline \multicolumn{2}{|l|}{ CHRONIC DISEASE $^{\dagger}$} \\
\hline Hypertension & $47(45,49)$ \\
\hline Diabetes & $16(14,17)$ \\
\hline Chronic obstructive pulmonary disease & $6(5,6)$ \\
\hline Heart disease & $8(7,9)$ \\
\hline Cancer & $15(14,17)$ \\
\hline Asthma & $12(11,13)$ \\
\hline Arthritis & $40(38,42)$ \\
\hline Stroke & $6(5,7)$ \\
\hline
\end{tabular}

*Percentages may not sum to 100 due to rounding tAsked only of adults

$\$$ Three-part screener question to determine whether respondent required assistance with activities of daily living (ADL) or instrumental activities of daily living ( $i A D L)$

\$Measure of non-specific psychological distress. "Sum of six psychological distress variables, each on a scale of $0=$ "none of the time" to $4=$ "all of the time"

\section{RESULTS}

\section{Population Characteristics}

In 2015, the MEPS included 7161 patients with primary care who visited their primary care office at least once that year, representing 101,159,263 Americans. They were predominantly female $(55 \%)$, middle-aged (40 years old), white (62\%), partnered (52\%), at least high school-educated (69\%), and employed (58\%; Table 1). Most were privately insured (62\%). Many reported chronic diseases, including $47 \%$ with hypertension, $40 \%$ with arthritis, $15 \%$ with cancer, and $16 \%$ with diabetes.

\section{Practice Characteristics}

Fifty-five percent of patients were served at independently owned practices, $19 \%$ at hospital-owned practices, and $20 \%$ at nonprofit/government/academic-owned practices (Table 2).

Table 2 Characteristics of United States Primary Care Practices, 2015

\begin{tabular}{|c|c|}
\hline Characteristic & $\begin{array}{l}\text { Mean \% } \\
(95 \% \mathrm{CI})^{*} \\
(n=7161 \\
\text { patients })\end{array}$ \\
\hline \multicolumn{2}{|l|}{ Practice organizational structure } \\
\hline \multicolumn{2}{|l|}{ Ownership description } \\
\hline Independent & $55(52,57)$ \\
\hline Physician network owned by hospital & $19(17,22)$ \\
\hline Nonprofit/government/academic medical center & $20(18,22)$ \\
\hline Health maintenance organization & $1(1,2)$ \\
\hline Corporation-owned & $3(2,4)$ \\
\hline Other & $1(1,2)$ \\
\hline More than one location & $46(43,48)$ \\
\hline Multispecialty group practice & $37(34,39)$ \\
\hline \multicolumn{2}{|l|}{ Physicians per practice } \\
\hline Solo & $25(23,27)$ \\
\hline $2-10$ & $53(51,56)$ \\
\hline$>10$ & $22(20,24)$ \\
\hline $\begin{array}{l}\text { Practices with nurse practitioners and/or physician } \\
\text { assistants }\end{array}$ & $72(70,74)$ \\
\hline \multicolumn{2}{|l|}{ Practice capability } \\
\hline \multicolumn{2}{|l|}{ EHR capabilities } \\
\hline Practice uses electronic health record & $90(89,92)$ \\
\hline $\begin{array}{l}\text { Electronic health record sends guideline/screening } \\
\text { reminders }{ }^{\dagger}\end{array}$ & $88(87,90)$ \\
\hline $\begin{array}{l}\text { Exchange secure messages with patients via } \\
\text { electronic health record } \\
\text { Other capabilities }\end{array}$ & $78(76,80)$ \\
\hline Certified patient-centered medical home & $41(38,44)$ \\
\hline Case manager coordinates patient care & $51(49,54)$ \\
\hline Patient follow-up occurs within $48 \mathrm{~h}$ of discharge & $72(70,75)$ \\
\hline $\begin{array}{l}\text { Routinely sends reminders for preventive and follow- } \\
\text { up care }\end{array}$ & $89(88,91)$ \\
\hline In-clinic x-ray capability & $34(31,37)$ \\
\hline Same-day appointment availability & $95(94,96)$ \\
\hline MD receives individualized quality report & $89(88,90)$ \\
\hline \multicolumn{2}{|l|}{ Payment orientation } \\
\hline $\begin{array}{l}\text { Participate in accountable care organization } \\
\text { (Medicare or private) }\end{array}$ & $44(41,47)$ \\
\hline Physician paid a base salary & $74(72,76)$ \\
\hline Capitated contracts & $46(43,49)$ \\
\hline \multicolumn{2}{|l|}{ Medicaid coverage } \\
\hline$<10 \%$ & $33(30,36)$ \\
\hline $10-50 \%$ & $38(35,42)$ \\
\hline$>50 \%$ & $28(26,31)$ \\
\hline
\end{tabular}

* Percentages may not sum to 100 due to rounding

tOf the $90 \%$ of practices that used electronic health records 
Forty-six percent and $37 \%$ of patients were cared for at primary care practices that were part of multisite and multispecialty practices, respectively. About $25 \%$ of patients were served by solo practices, $53 \%$ by practices with $2-10$ physicians, and $22 \%$ at practices with more than 10 physicians. Seventy-two percent were served at practices with at least one nurse practitioner or physician assistant.

Certified PCMH practices served $41 \%$ of patients, and practices using case managers to coordinate care served $51 \%$ of patients. EHRs were found in practices serving $90 \%$ of patients. Of this $90 \%$, EHRs provided guideline/screening reminders for $88 \%$ and were able to send secure messages for $78 \%$. Practices serving $72 \%$ of patients reported that a practice member would contact a patient discharged from the hospital within $48 \mathrm{~h}$ of discharge. Practices serving $95 \%$ of patients could provide same-day appointment availability. Inclinic x-ray capability was available to $34 \%$ of patients.

Forty-four percent of patients were served by practices that participated in a Medicare or private ACO, and a similar percentage of patients (46\%) were seen at practices that participated in at least one capitated contract. Practices serving $74 \%$ of patients paid physicians a base salary.

\section{Disparities in Practice Capabilities}

Patients in the South were served at practices with fewer capabilities (Table 3). For example, $33 \%$ of patients in the South were served at PCMHs, compared to $46 \%$ outside the South (adjusted difference, 14\% [95\% CI, 9\% to 19\%]). Practices in the South also used case managers less frequently (adjusted difference, 13\% [95\% CI, 8\% to 18\%]), had lower use of EHR reminders (adjusted difference, 5\% [95\% CI, 0\% to $9 \%$ ]) and messaging (adjusted difference, $6 \%$ [95\% CI, $1 \%$ to $10 \%]$ ), and less commonly sent reminders for preventive and follow-up care (adjusted difference, $6 \%$ [95\% CI, 2\% to $10 \%]$ ) or provided same-day appointment availability (adjusted difference, $5 \%$ [95\% CI, $2 \%$ to $7 \%]$ ).

Uninsured patients were less likely to be served at a practice that used an EHR (83\% vs. 90\%; adjusted difference, $9 \%$ [95\% CI, $2 \%$ to $16 \%]$ ) and that exchanged secure messages with patients $(67 \%$ vs. $78 \%$; adjusted difference, $13 \%$ [95\% CI, $2 \%$ to $25 \%]$ ).

We found no significant differences in practice capabilities among practices serving primary care patients who were black or had less than a high school education. We also observed no differences in characteristics among practices serving children versus adults.

\section{DISCUSSION}

Despite the prevailing notion that practice capabilities are lagging and practices are merging into larger practice organizations or being purchased by health systems and hospitals, we demonstrate in this nationally representative sample that most patients are served by primary care practices that are 
independently owned, and almost all have implemented EHRs. A large minority are certified PCMHs and participate in innovative payment models. Disparities in nearly all practice capabilities were evident for patients in the South (where $36 \%$ of visits occurred) and, to a lesser degree, for uninsured patients, but not for blacks, those with less than a high school education, or children.

This 2015 snapshot of United States primary care demonstrates a system that has made important strides but still has more to do before providing truly comprehensive care. $^{21,22}$ About one in five Americans cannot exchange secure messages with their clinician, two in three cannot obtain imaging in the office, and about half lack access to case management within primary care. Some of these shortcomings may explain why primary care faces stiff competition from less traditional sites of care such as urgent care clinics and retail clinics. ${ }^{23}$

Our findings build on prior surveys and provide updated information about the current practice context. The most comparable nationally representative data available on practice organization and capability comes from the National Ambulatory Medical Care Survey (NAMCS), although it reports capabilities by visit, not on a population basis of those who made a visit, and reports on all visits, not only those to primary care. ${ }^{24}$ In $2012,11 \%$ of visits occurred in practices of 11 or more physicians; we found that $22 \%$ of patients in 2015 were cared for in practices that had 11 or more physicians. NAMCS found that only $18 \%$ of visits occurred at certified PCMHs in 2012; we found that $41 \%$ of primary care patients were served by PCMHs. NAMCS also reports that $78 \%$ of visits used an EHR in 2012; our data suggest that practices used EHRs for $90 \%$ of patients. Data on ACO participation from the Medscape Physician Compensation Report suggests that $33 \%$ of physicians participated in ACOs, compared to our finding that practices participating in ACOs served $44 \%$ of patients. ${ }^{25}$ Data from Physician Compare based on the Medicare Provider Enrollment, Chain, and Ownership System may differ somewhat from our findings. In 2015, Muhlestein and Smith found that only $19 \%$ of primary care physicians practiced in solo or two-person practices, compared to our finding that solo practitioners served $25 \%$ of primary care patients. ${ }^{26}$ However, their unit of analysis was the practice, not the patient, and their data only reflected primary care physicians in Physician Compare, not the nation's primary care physicians.

Our study has limitations. First, respondents varied among practices, and some may not have had full knowledge of all aspects of the practice. Second, the MOS has no prior data for comparison. Other large surveys such as NAMCS may not be directly comparable due to sampling of visits, not patients. Neither publicly report practice-level measures. Third, when examining disparities in practice capabilities, some of our samples were likely too small. Fourth, residual confounding may exist between potential patient disparities and practice characteristics. Fifth, we report on in-office x-ray capabilities, but some practices might have had ready access to x-ray in the same or a nearby building.

\section{CONCLUSIONS}

Primary care patients were served by mostly independently owned and small practices that employed health information technology, had patient-facing capabilities, and undertook innovative payment models. Patients in the South had access to practices with fewer capabilities than those in the rest of the country; future studies should examine how these gaps affect outcomes and should target improvements in the South. Future work should also assess changes over time as MACRA begins to impact the primary care landscape.

Corresponding Author: David Michael Levine, MD MPH MA; Division of General Internal Medicine and Primary Care Brigham Health, Boston, MA, USA (e-mail: dmlevine@bwh.harvard.edu).

Author Contributions David Levine had full access to all of the data in the study and takes responsibility for the integrity of the data and the accuracy of the data analysis.

Study concept and design: all authors.

Acquisition, analysis, or interpretation of data: all authors. Drafting of the manuscript: Levine.

Critical revision of the manuscript for important intellectual content: all authors.

Statistical analysis: Levine.

Administrative, technical, or material support: Levine.

Study supervision: Landon, Linder.

\section{Compliance with Ethical Standards:}

Conflict of Interest: All authors declare that they have no conflict of interest.

Financial Support: Dr. Levine has received funding support from an Institutional National Research Service Award (T32HP10251), the Ryoichi Sasakawa Fellowship Fund, and Brigham and Women's Hospital Division of General Internal Medicine and Primary Care.

The NIH had no role in the design or conduct of the study; the collection, management, analysis, or interpretation of the data; or the preparation, review, or approval of the manuscript.

\section{REFERENCES}

1. Boult C, Wieland GD. Comprehensive primary care for older patients with multiple chronic conditions. JAMA. 2010;304(17):1936. https://doi. org/10.1001/jama.2010.1623.

2. Macinko J, Starfield B, Shi L. Quantifying the health benefits of primary care physician supply in the United States. Int $\mathrm{J}$ Health Serv. 2007;37(1):111-26. https://doi.org/10.2190/3431-G6T737M8-P224.

3. Bitton A, Ratcliffe HL, Veillard JH, et al. Primary health care as a foundation for strengthening health systems in low- and middle-income countries. J Gen Intern Med. 2017;32(5):566-71. https://doi.org/10. 1007/s11606-016-3898-5.

4. Pesec M, Ratcliffe HL, Karlage A, Hirschhorn LR, Gawande A, Bitton A. Primary health care that works: the Costa Rican experience. Health Aff. 2017;36(3):531-38. https://doi.org/10.1377/hlthaff.2016.1319.

5. O'Malley AS, Rich EC. Measuring comprehensiveness of primary care: challenges and opportunities. J Gen Intern Med. 2015;30 Suppl 3:56875. https://doi.org/10.1007/s11606-015-3300-z.

6. Gaynor M, Mostashari F, Ginsburg PB. Making health care markets work. JAMA. 2017;316(16):1711-13. https://doi.org/10.1001/jama. 2017.1173. 
7. Kane CK, Emmons DW. New data on physician practice arrangements: private practice remains strong despite shifts toward hospital employment. https://www.ama-assn.org/sites/default/files/media-browser/ premium/health-policy/prp-physician-practice-arrangements_0.pdf. Accessed June 22, 2017.

8. Cutler DM, Scott Morton F. Hospitals, market share, and consolidation. JAMA. 2013;310(18):1964. https://doi.org/10.1001/jama.2013. 281675.

9. Jha AK. How would the next president ensure competitiveness in the health care marketplace? JAMA. 2017;317(2):125-6. https://doi.org/10. 1001/JAMA.2016.17772.

10. Levine DM, Healey MJ, Wright A, Bates DW, Linder JA, Samal L. Changes in the quality of care during progress from stage 1 to stage 2 of meaningful use. J Am Med Inform Assoc. 2016;24(2):ocw127. https:// doi.org/10.1093/jamia/ocw127.

11. Kessler RC, Andrews G, Colpe LJ, et al. Short screening scales to monitor population prevalences and trends in non-specific psychological distress. Psychol Med. 2002;32(6):959-76. http://www.ncbi.nlm.nih. gov/pubmed/12214795. Accessed 29 Febr 2016.

12. Friedberg MW, Schneider EC, Rosenthal MB, Volpp KG, Werner RM. Association between participation in a multipayer medical home intervention and changes in quality, utilization, and costs of care. JAMA. 2014;311(8):815-25. https://doi.org/10.1001/jama.2014.353.

13. Salzberg CA, Bitton A, Lipsitz SR, et al. The impact of alternative payment in chronically Ill and older patients in the patient-centered medical home. Med Care. 2017;55(5):483-92. https://doi.org/10.1097/ MLR.0000000000000694.

14. Medical Expenditure Panel Survey Medical Provider Component. 2013 Annual Methodology Report. Rockville, MD; 2013. http://meps.ahrq. gov/mepsweb/data_files/publications/annual_contractor_report/mpc_ ann_cntrct_methrpt.shtml\#changes. Accessed 18 March 2016.

15. Fiscella K, Franks P, Gold MR, Clancy CM. Inequality in quality. JAMA. 2000;283(19):2579. https://doi.org/10.1001/jama.283.19.2579.

16. Trivedi AN, Zaslavsky AM, Schneider EC, Ayanian JZ. Trends in the quality of care and racial disparities in Medicare managed care. N Engl J Med. 2005;353(7):692-700. https://doi.org/10.1056/NEJMsa051207.
17. Fisher ES, Wennberg JE. Health care quality, geographic variations, and the challenge of supply-sensitive care. Perspect Biol Med. 2003;46(1):6979. http://www.ncbi.nlm.nih.gov/pubmed/12582271. Accessed June 22, 2017.

18. Machlin S, Yu W, Zodet M. Medical expenditure panel survey computing standard errors for MEPS Estimates. Rockville, MD: Agency for Healthcare Research and Quality; 2005. http://meps.ahrq.gov/ mepsweb/survey_comp/standard_errors.jsp. Accessed 22 Jan 2016.

19. Cohen S, Machlin S. Nonresponse adjustment strategy in the household component of the 1996 Medical Expenditure Panel Survey. J Econ Soc Meas. 1998;25:15-33.

20. Zodet M, Chowdhury S, Machlin S, Cohen J. Linked designs of the MEPS medical provider and organization surveys. https://ww2.amstat.org/ sections/srms/Proceedings/y2016/files/389649.pdf. Accessed 16 Oct 2017.

21. Linder JA, Levine DM. Health care communication technology and improved access, continuity, and relationships. JAMA Intern Med. 2016;176(5):643. https://doi.org/10.1001/jamainternmed.2016.0692.

22. Levine DM, Linder JA, Landon BE. The quality of outpatient care delivered to adults in the United States, 2002 to 2013. JAMA Intern Med. 2016;176(12):1778. https://doi.org/10.1001/jamainternmed.2016. 6217.

23. Levine DM, Linder JA. Retail clinics shine a harsh light on the failure of primary care access. J Gen Intern Med 2015. https://doi.org/10.1007/ s11606-015-3555-4.

24. Hing E, Kurtzman E, Lau DT, Taplin C, Bindman AB. Characteristics of Primary Care Physicians in Patient-centered Medical Home Practices: United States, 2013. Natl Heal Stat Reports Number. 2017;101. https:// www.cdc.gov/nchs/data/nhsr/nhsr101.pdf. Accessed 14 March 2017.

25. Peckham C. Medscape Physician Compensation Report 2016; 2016. http://www.medscape.com/features/slideshow/compensation/2016/ public/overview\#page $=19$.

26. Muhlestein DB, Smith NJ. Physician consolidation: rapid movement from small to large group practices, 2013-15. Health Aff (Millwood). 2016;35(9): 1638-42. https://doi.org/10.1377/hlthaff.2016.0130. 